\title{
Land management institution as a key confinement of urbanization in Baotou, China-Application of proposed endogenous urbanization model $^{\text {is }}$
}

\author{
Yongjiao $\mathrm{Wu}^{\mathrm{a}, \mathrm{b}}$, Suocheng Dong ${ }^{\mathrm{b}, *}$, Jun Zhai ${ }^{\mathrm{c}}$, Dingxuan Huang ${ }^{\mathrm{a}}$, Zhengyu Huang ${ }^{\mathrm{a}}$ \\ a School of Management, Guilin University of Technology, Guilin 541004, China \\ ${ }^{\mathrm{b}}$ Institute of Geographic Sciences and Natural Resources Research, Chinese Academy of Sciences, Beijing 100101, China \\ ' Satellite Environmental Center, Ministry of Environmental Protection, Beijing 100094, China
}

\section{A R T I C L E I N F O}

\section{Article history:}

Received 13 October 2015

Received in revised form 18 March 2016

Accepted 23 April 2016

Available online 24 June 2016

\section{Keywords:}

Urban expansion

Land management institution

Growth model

Technological progress

Baotou city

China

\begin{abstract}
A B S T R A C T
China has been experiencing rapid urbanization, with a large amount of rural land converted into urban land, leading to debate by researchers and governments. This study investigates the endogenous factors influencing urban expansion and quantifies their effects to promote intensive and sustainable urban land use in order to realize new-type urbanization, by employing GIS technology and an endogenous growth model. The simulation results explain the expansion of urban land in the case of Baotou city, China. The result shows that the land management institution(LMI) has played a critical role in urban land expansion in Baotou city. Its multiplier effect reaches 0.166 , which means a one percentage point increase in the strength of LMI leads to a $0.166 \%$ increase in urban land area. The presented analysis reveals four main findings. Firstly, the major factors influencing urban expansion are (LMI), urban disposable income per capita, the secondary and tertiary industry, technological progress, and population density. Secondly, LMI has a critical influence on urban expansion. Thirdly, technological progress has a positive effect on urban expansion by merging into the secondary and tertiary industry. Finally, population density and the tertiary industry have a dampening effect on urban expansion. According to the analysis, we suggest that the central government in China should regulate the behavior of local governments to reduce principal-agent risk, as they hold the state land property rights as the trustee of the public. Meanwhile, the government should pay more attention to guiding technological progress by promoting industrial transformation and economic quality, not just focusing on economic quantity, especially for resource-based cities.
\end{abstract}

(c) 2016 Elsevier Ltd. All rights reserved.

\section{Introduction}

With considerable economic development and population increases at the global scale, various cities have been undergoing rapid urbanization. It is projected that by 2050, the share of the urban population globally will have increased to $66 \%$ from $54 \%$ in 2014, with China's proportion rising to over 77\% (United Nations, 2014). China has experienced unprecedented economic growth and population urbanization since its economic reform and opening up. Nowadays, China is the global engine of not only economic growth

\footnotetext{
This paper was supported by the project of National Natural Science Foundation of China, Grant No. 41271556.

* Corresponding author.

E-mail addresses: moonsun0403@163.com (Y.Wu),dongsc3@163.com (S. Dong), zhaij@lreis.ac.cn (J. Zhai), huangdingxuan@126.com (D. Huang), m13481392124@163.com (Z. Huang).
}

but also urban population growth (Quan et al., 2015). Corresponding to this rapid urbanization, urban land in China dramatically expanded between 1980 and 2011, increasing by 78.5\% compared with an urban population growth rate of $46 \%$ at the expense of rural land such as farmland, grassland, and forestry (Li et al., 2011; Jiang et al.,2013; Jiang et al., 2014; Zhao et al., 2014).

Rapid urban expansion has raised severe challenges for the environment, housing, food security, and social conflicts (He et al., 2008; Angel et al., 2011; Bai et al., 2014). These challenges have encouraged governments and scholars to pay more attention to understanding the dynamics of urban expansion in China (Ding, 2003; Wang et al., 2012a,b). The new leadership in China has placed urbanization as one of its core subjects in its policy agenda (Wei and Ye, 2014). To optimize the quality of urbanization, China put forward its "new-type urbanization planning" program in 2014, which aims to transform traditional rural-urban development into people-oriented rural-urban development. 

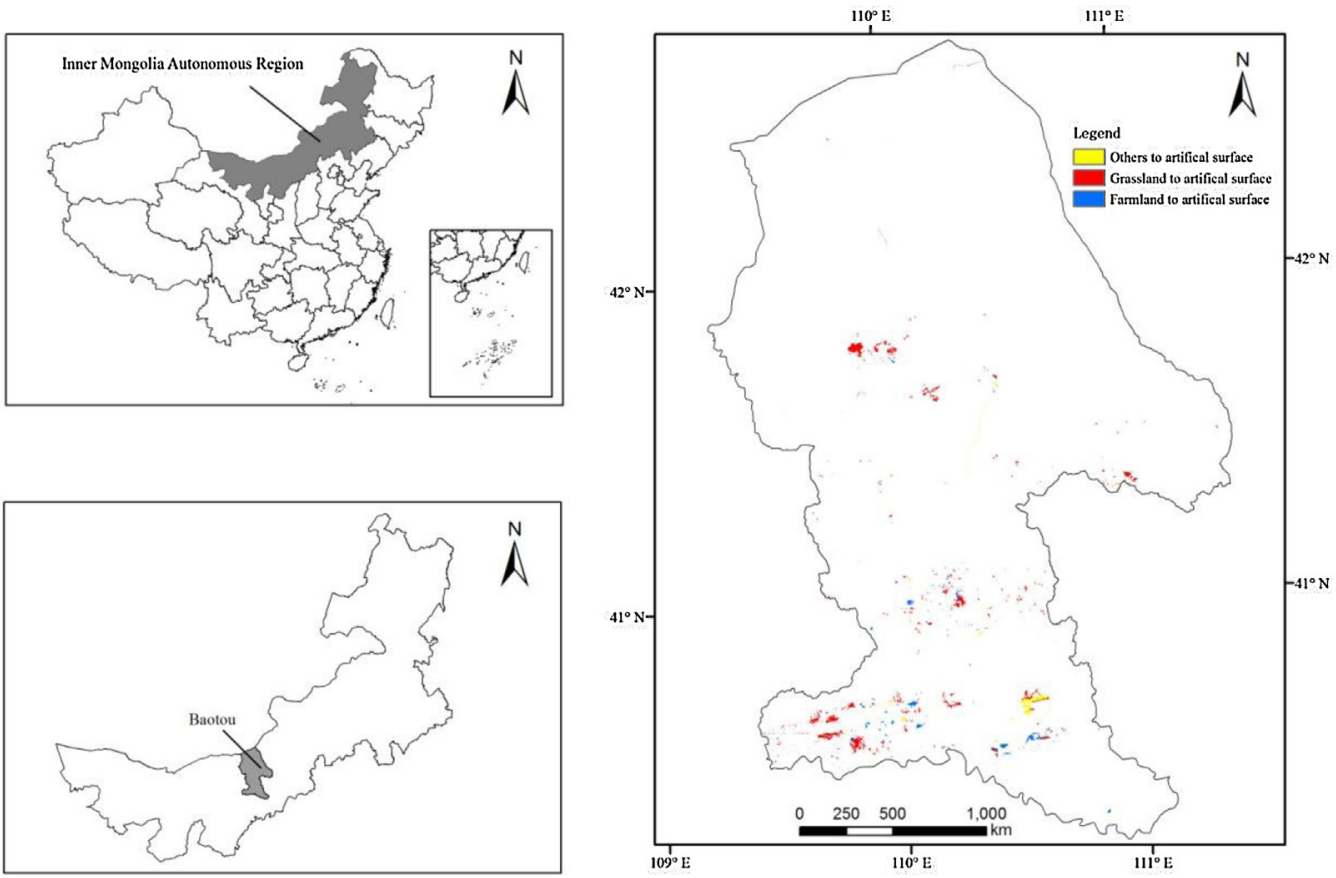

Fig. 1. Location of Baotou city and land conversion (2000-2010).

To explain the positive and negative consequences of rapid urban expansion, scholars have examined the extent, process, and consequences of urbanization and land use change in recent decades. They mainly focus on the following several aspects. (1) GIS technology and spatial modeling have been widely introduced to investigate landscape change and the spatial patterns of urban expansion (Verburg et al., 1999; Xiao et al., 2006; Liu and Zhang, 2008; Kumar et al., 2011; Wang et al., 2012a; Gao et al., 2013; Mondal et al., 2015; Zeng et al., 2015; Zhao et al., 2015). For example, Xiao et al. (2006) categorized spatial patterns into special objectives, social-political intervention, and normal urban growth. (2) Studies have quantified the driving forces of urban expansion by using principle component analysis, multiple linear regression, logistic regression, spatial regression, panel models, and stochastic cellular automata models (Kuang et al., 2009; Wu et al., 2010; Seto et al., 2011; Upton et al., 2014; Dorning et al., 2015). Here, population growth, urbanization, industrialization, economic growth, technological progress, physical conditions, marketization, and land use policies have been tested as the major drivers (He et al., 2008; Li et al., 2011).

Currently, researchers are focusing on the effects of land management institution (LMI) on urban expansion since this has less influence in shaping urban development than market forces in many cities during their early development (Huynh, 2015). Many Chinese studies have investigated the importance of LMI on urban expansion (Taylor, 1998; Wang et al., 2012b; Christensen, 2014; Huang et al., 2015), as this plays a critical role in land use under land property rights. China's land property rights are divided into public ownership (i.e., belonging to the state) and collective ownership (i.e., belonging to farmers' collectives). In China's land system, urban land belongs to the state, while rural land belongs to farmers' collectives (China Financial 40 Peolple Forum Group, 2013). Under this arrangement, China's local government implements the property rights of state land as the national trustee. Furthermore, in some senses, China's local government has the ultimate right to transform rural land into urban land.

These previous studies have provided a good theoretical basis and reference for this study, such as the GIS technology use and major factors selection. However, most of these previous studies have focused on: (1)coupling the relationship between the positive and negative consequences of rapid urban expansion;(2) the qualitative analysis of the effects of LMI on urban expansion or simply selecting subjective weighting method to quantify effects of land use policy on land expansion; (3) taking LMI as an exogenous variable in modeling the dynamic change of urban expansion. Meanwhile, they can't explain well why the urban land expansion exhibit so big differences in regions, China, even in the regions with the same economic development and natural endowments.

By contrast, in this study, we take LMI as an endogenous variable. Further, we introduce an endogenous growth theory (Romer, 1994) and Gujarati method (Li and Ye, 2000) to construct the model in order to simulate the driving forces of urban expansion and to uncover the LMI choices that cause the rate of urban land growth of the residual to vary across different LMIs. Then, to analyze the influence of LMI on urban expansion, we discuss dynamic changes in urban land under different LMI scenarios. In particular, we examine the case of Baotou city, China.

\section{Study area}

Baotou city is located in the mid-west of the Inner Mongolia autonomous region at $109^{0} 25^{\prime}-110^{0} 25^{\prime} \mathrm{E}, 40^{0} 25^{\prime}-42^{0} 50^{\prime} \mathrm{N}$ (Fig. 1) and is $27,768 \mathrm{~km}^{2}$ in size. It is an important resource extraction city. Furthermore, it is an important industrial base in China, while its rate of urban development has remained high since the West Development Strategy of China from the 2000s.

During 1999-2011, industrial output value increased from USD 4.61 billion to USD 58.52 billion at an average annual growth rate of $23.59 \%$, far exceeding China's average. It constantly increased along with the rapid economic development in Baotou city. The average annual growth rate of urban disposable income per capita reached 19\%, far more than China's average level from 1999 to 2011. Meanwhile, technological progress have kept a stable rate, the average annual rate of $58.04 \%$; In the same period, the proportion of the city's urban population increased from $69.1 \%$ to $80.5 \%$, while urban built-up areas expanded from $150 \mathrm{~km}^{2}$ to $185 \mathrm{~km}^{2}$. As shown in 
Table 1

Transition matrix of the land use types of Baotou city from 2000 to 2010 unit: km².

\begin{tabular}{|c|c|c|c|c|c|c|c|c|}
\hline & Pasture & Farmland & forestry & wetland & developed land & others & total & net change \\
\hline Pasture & 0.00 & 30.44 & 56.39 & 15.23 & 145.38 & 14.84 & 262.28 & -144.10 \\
\hline farmland & 21.32 & 0.00 & 2.85 & 13.48 & 39.64 & 0.81 & 78.10 & -27.71 \\
\hline Forestry & 12.01 & 1.23 & 0.00 & 0.04 & 1.72 & 0.14 & 15.14 & 45.83 \\
\hline wetland & 56.86 & 11.44 & 1.07 & 0.00 & 6.21 & 36.25 & 111.83 & -80.66 \\
\hline developed land & 5.03 & 6.81 & 0.53 & 0.92 & 0.00 & 0.34 & 13.63 & 200.65 \\
\hline others & 22.96 & 0.47 & 0.14 & 1.50 & 21.33 & 0.00 & 46.40 & 5.98 \\
\hline Total & 118.18 & 50.39 & 60.97 & 31.17 & 214.28 & 52.38 & & \\
\hline
\end{tabular}

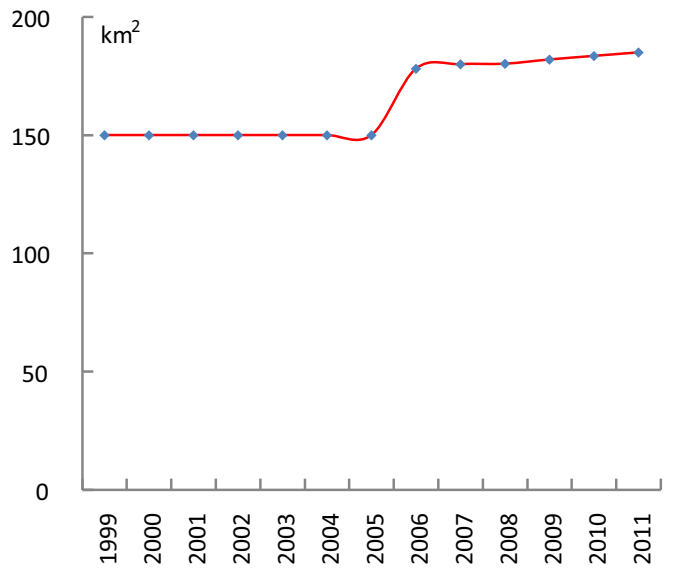

Fig. 2. Urban land areas of Baotou city (1999-2011).

Fig. 2, urban land has rapidly expanded at the expense of grassland and farmland. The local government kept the stable strength of LMI before 2007, however, they suddenly strengthened the LMI to increase built-up land area in 2006 when the central government in China issued the Notice on Adjusting the Policy of Compensation for the Use of Land for New Construction Land in 2006 and implemented it in 2007.

Baotou city also belongs to the Shaanxi-Gansu-Ningxia-Inner Mongolia zone along the Yellow River and is an important city in water-limited Northwest China. The zone is a key shelterbelt with afforestation used as windbreak for ensuring China's ecological security, which has been identified by China (Dong et al., 2010). This is a marginal region of western China with a fragile ecology, less developed economy, and imbalanced development status. Hence, it is faced with the dual dilemma of economic development and environmental protection. Hence, it is significant and meaningful to investigate the major endogenous factors influencing urban expansion in Baotou city.

\section{Data and methods}

\subsection{Data and processing}

In this study, the data come from the statistical yearbook of Baotou City and the City Construction Statistical Yearbook. Original data were pre-processed to eliminate the impact of the unit, using the consumer price index $(\mathrm{CPI}, \mathrm{P} 1999=100)$ to reflect the real economic change. Here, urban land area represents the urban built-up area, while urban population is represented by the permanent resident population. Landsat ETM/TM images were collected for LUCC classification from the 2000Landsat ETM/ET (127/31, 2000-07-15; 127/32, 2000-06-13; 128/31, 2002-06-10; $128 / 32,2000-11-11)$ and 2010 Landsat ETM/ET(127/31, 2010-09$05 ; 127 / 32,2009-06-30 ; 128 / 31,2010-09-04 ; 128 / 32,2010-08-27$ ) data sets, spatial resolution is $30 \mathrm{~m}$. Based on 2000Landsat ETM/ET, 2010Landsat ETM/TM, land use data were derived by artificial dig- ital interpretation (Fig. 3 and Table 1). In Table 1, the numbers are the land areas transformed from a certain type(row) to another type(column) during the period 2000-2010. For example, the number 30.44 (row1,column2) is the land area converted from pasture to farmland during this period.

\subsection{Methods}

\subsubsection{Endogenous growth theory}

Endogenous growth theory holds that economic growth is primarily the result of endogenous and not external forces(Romer, 1994). Endogenous growth theory is the primary way in which to explain the phenomenon of modern growth. The model framework can interpret how the major endogenous variables influence growth (Romer, 1994; Sachs and Larrain, 2003). The general model is expressed as follows:

$$
\left\{\begin{array}{l}
\mathrm{Y}=\mathrm{f}(\mathrm{K}, \mathrm{L}, \mathrm{T}) \\
\mathrm{Y}=\mathrm{A} K^{\alpha} L^{\beta} T^{\delta} \\
\Rightarrow \frac{\Delta Y}{Y}=\alpha \frac{\Delta K}{K}+\beta \frac{\Delta L}{L}+\delta \frac{\Delta T}{T}
\end{array}\right.
$$

Here, K, L, and T denote the endogenous factors influencing growth, while $\alpha, \beta, \delta$ present the effect multipliers of these driving forces (i.e., affecting efficiency). The change rate $(\Delta Y / Y)$ equals the sum of the each factor's effect multiplier multiplied by the change rate of the driving forces $\left(\frac{\Delta Y}{Y}=\alpha \frac{\Delta K}{K}+\beta \frac{\Delta L}{L}+\delta \frac{\Delta T}{T}\right)$.

Based on the literature and actual situation of natural resources and socioeconomic development in Baotou city, we carried out a cointegration analysis of the related driving forces. We chose urban built-up area (Land) as the dependent variable, and LMI, urban land population density (Pop), secondary industry added value $\left(\operatorname{Ind}_{2}\right)$, tertiary industry added value ( $\operatorname{Ind}_{3}$ ), technological progress $(\mathrm{Tec})$, and urban disposable income per capita (Inc) as the endogenous independent variables.

\subsubsection{Quantification of factors and model construction}

Technological progress can improve socioeconomic development(Sachs, J.D. et al., 2003) To quantify the technological progress index, we used Han (2012) method. To disclose urban technological progress objectively, we employed the entropy method to calculate each index weight (Table 2).

To quantify LMI, we used a dummy variable. When a variable has experienced a sudden change at a certain point in time, it is commonly caused by a certain policy implementation (Wu and Dong, 2010). In Baotou city, urban land was stable during 1999-2005. In 2006, however, it suddenly changed and then rose stably (Fig. 2), because of the construction of the largest industrial park in China (Junyan Industrial Park) in 2006 (area $78 \mathrm{~km}^{2}$ ). Hence, we introduce the Gujarati method to quantify the LMI index in Baotou city as follows:

$$
\left\{\begin{aligned}
& 1999-2005 \rightarrow x_{5}=\exp (0) \\
& 2006-2011 \rightarrow x_{5}=\exp (1)
\end{aligned}\right.
$$



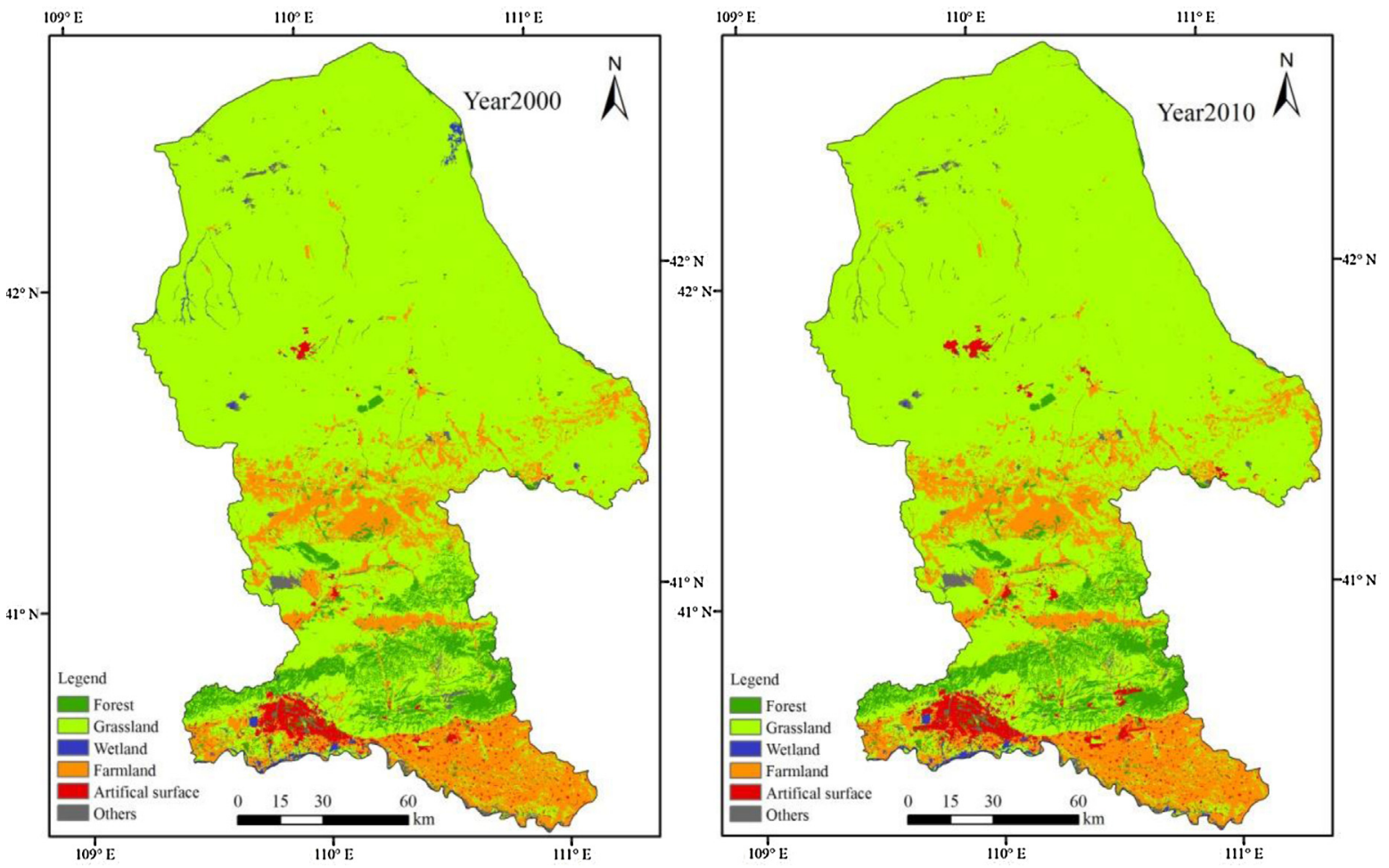

Fig. 3. Land use types between 2000 and 2010, Baotou city.

Then, we employ EVIEWS6.1 to model the simulation, with the results presented below:

$\left\{\begin{array}{l}\text { Land }=f\left(T e c, \text { LMI, Pop }, \text { Ind }_{2}, \text { Ind }_{3}, \text { Inc }\right) \\ \text { LnLand }=0.166 \mathrm{LMI}_{t}-0.049 \mathrm{Pop}_{(t-1)}+\frac{0.006}{\text { LnTec }_{t}} \text { LnInd }_{2}-\frac{0.015}{\text { LnTec }_{t}} \text { LnInd }_{3}+0.047 \text { Lnc }_{(t-1)}\end{array}\right.$
T test: $(19.94)^{* * *}(-2.27)^{*}(1.72)^{*}(-2.29)^{*}(4.38)^{* * *}$

$\mathrm{R}^{2}=0.99 \mathrm{DW}=2.06{ }^{* * *},{ }^{* *}$, and ${ }^{*}$ mean significance at the $1 \%$,

$5 \%$, and $10 \%$ levels)

Here, $t$ means time.

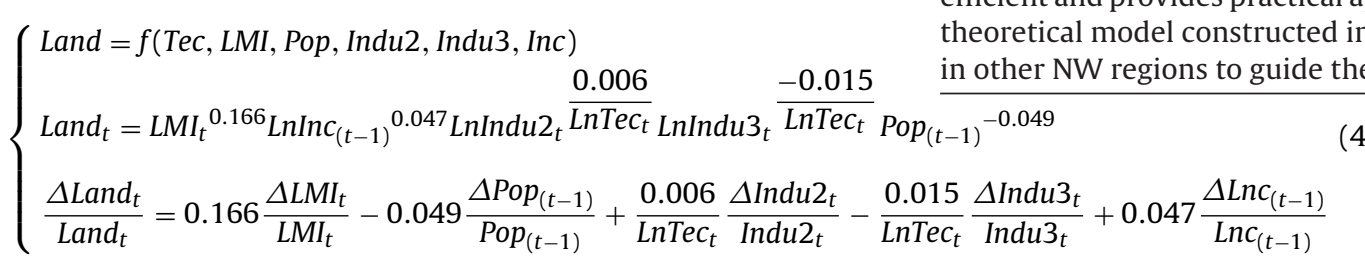

The fitting degree of this model is relatively high, reaching $99 \%$. The model has passed the $\mathrm{F}$ test, and all the parameters have passed the $T$ test. No autocorrelation exists since the DW $=2.06$ between
Table 2

Index weight of technological progress, Baotou city.

\begin{tabular}{ll}
\hline Index & Weight \\
\hline Education investment (USD) & 0.117 \\
Per capita road areas (kilometers/104 people) & 0.061 \\
Urban transportation and communication cost (USD) & 0.118 \\
R\&D investment (USD) & 0.115 \\
College students (per thousand of the population) & 0.076 \\
Scientific research/technology service and geological & 0.089 \\
$\quad$ prospecting personnel & \\
Foreign direct investment (USD) & 0.074 \\
Proportion of foreign trade imports to exports (\%) & 0.035 \\
Public finance expenditure (USD) & 0.101 \\
Finance income (USD) & 0.106 \\
Per capita urban population disposable income (USD) & 0.076 \\
Proportion of non-agriculture added value to GDP (\%) & 0.031 \\
(Note: weight calculated by using the entropy method) & \\
\hline
\end{tabular}

the [1.95-2.15] statistics without autocorrelation. This model is efficient and provides practical application for the rationality of the theoretical model constructed in this paper and can be easily used

\section{Results}

\subsection{Characteristics of urbanization in Baotou, 1999-2011}

Accompanying the rapid regional economic and population growth, urban land expanded from $150 \mathrm{~km}^{2}$ in $1999-185 \mathrm{~km}^{2}$ in 2011, at an average annual growth rate of $1.7 \%$ (Fig. 2), at the expense of farmland and grassland (Fig. 3 and Table 1). Specifically, developed land (residential, industrial, traffic, mining land) increased by $200 \mathrm{~km}^{2}$ at the expense of grassland and farmland. In which, about $145 \mathrm{~km}^{2}$ of grassland and $39 \mathrm{~km}^{2}$ of farmland converted into developed land. In addition, about $50.4 \mathrm{~km}^{2}$ of farmland was converted from other types of land and $78.1 \mathrm{~km}^{2}$ into other types of land. Significantly, high-quality farmland was converted 


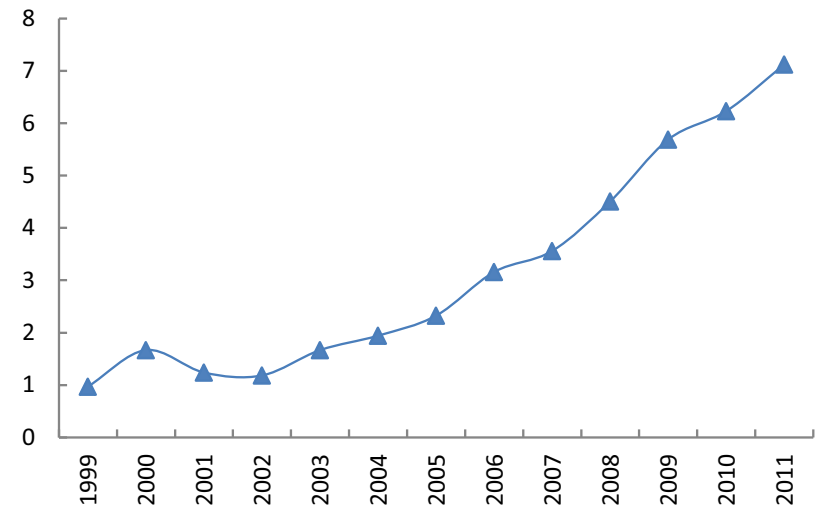

Fig. 4. Technological progress index in Baotou city (1999-2011).

into developed land, while low-quality farmland was generated following the compensation policy. During the same period, the net increase in the forestry area reached $45.8 \mathrm{~km}^{2}$, which came from grassland because of the government's strategy of returning farmland (grassland) to forestry in northwest China.

By comprehensively analyzing the TM image interpretation data and simulation results for Baotou city during recent decades, we can draw the following four conclusions. First, urban land expanded from grassland and farmland to become land for residence, mining, and industry. Second, the major endogenous factors influencing urban expansion are LMI, urban disposable income per capita, population density, secondary and tertiary industry, and technological progress. Further, their multiplier effects are 0.166, 0.047, -0.05 , $\frac{0.01}{\text { LnTect }_{t}}$, and $\frac{-0.01}{\text { LnTect }_{1}}$, respectively (technological progress is merged into industry to influence urban expansion). Third, before 2006, under local socioeconomic development, urban land did not change because of the stable LMI; hence, the effects on urban expansion from the major endogenous factors offset each other. Finally, in 2006 , urban land suddenly expanded by $28.1 \mathrm{~km}^{2}$ through the change in LMI arrangements.

\subsection{Major endogenous factors in urban expansion}

\subsubsection{Technological progress and industrial development}

Technological progress can promote both use efficiency and resource allocation efficiency. Under the process of urban development, technological progress directly increases land efficiency to delay urban sprawl. Through urbanization, technological progress has improved greatly in Baotou city. The technological progress index increased from 1.001 in 1999-7.123 in 2011 (Fig. 4). The simulation results indicate that technological progress affects resource use efficiency in the secondary and tertiary industry and thus urban expansion. The multiplier effects of the secondary and tertiary

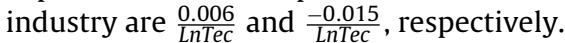

With technological progress, the multiplier effect of the secondary industry on urban expansion decreased from 0.012 in 1999-0.003 in 2011, suggesting technological progress optimizes the scale economies of the secondary industry. In Baotou city, a resource-based city, the development of the secondary industry relies on the heavy and chemical industries. Land is the carrier of mineral resources. Therefore, technological progress optimizes the land output elasticity in the secondary industry as land input increases. As a result, industrial land expanded by $16 \mathrm{~km}^{2}$ at an annual growth rate of $7.4 \%$. Although China has formulated a series of favorable strategies to transform industry and thereby promote sustainable development, the proportion of heavy industry remains high (82\% in 2011; Fig. 5).

Fig. 5 shows that the structure of the secondary industry is of low quality. The development of the heavy and chemical industries

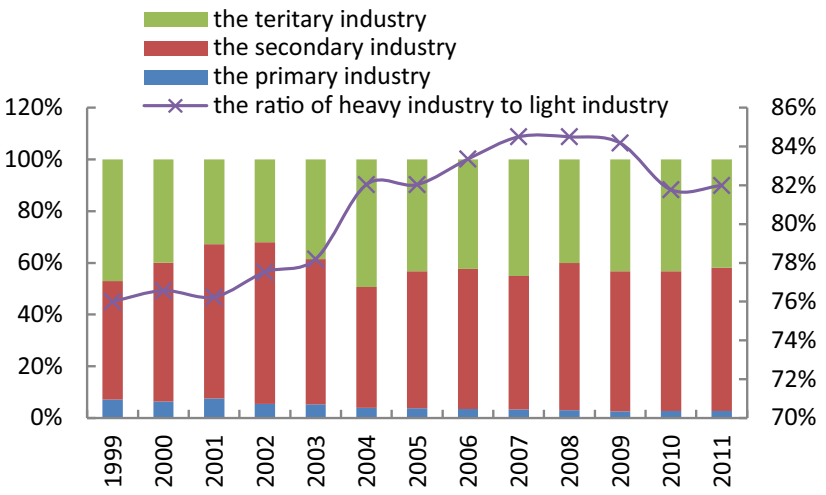

Fig. 5. Industrial structure of Baotou city (1999-2011).

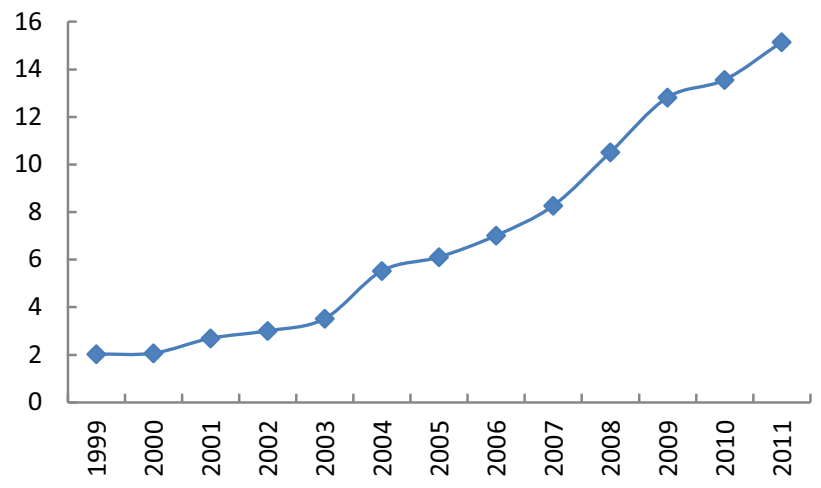

Fig. 6. Urban disposable income per capita index (1999-2011), Baotou city.

depends on exploiting more energy and mineral resources, which demands more rural land carrying mineral resources. Moreover, the extraction of minerals is often extremely polluting and thus has a huge environmental impact. Hence, such industrial development leads to a series of negative consequences for the environment such as water scarcity, water loss and land erosion, land desertification.

During the same period, the tertiary industry dampened urban expansion through technological progress, with a downward trend from 0.029 in 1999-0.008 in 2011. This result suggests a shortage of non-land resources and the sufficiency of land in the tertiary industry. From Fig. 6 and the simulation results, we show that the tertiary industry with continuing technological progress dampens urban expansion to protect agricultural land; however, the development of the tertiary industry is lagging. In addition, the allocation of land resources as well as other resources in the tertiary industry is inefficient, which is suboptimal, while the proportion of the tertiary industry is lower than that of the secondary industry (i.e., the development of the tertiary industry is lagging that of the secondary industry).

\subsubsection{Urban disposable income per capita}

Per capita income has a significant influence on housing demand (Leung, 2001). Fig. 6 shows that it constantly increased along with the rapid economic development in Baotou city. The average annual growth rate of urban disposable income per capita reached $19 \%$, far more than China's average level from 1999 to 2011. With this constantly increasing income per capita, housing area per capita rose from $8 \mathrm{~m}^{2}$ to $33 \mathrm{~m}^{2}$ between 1999 and 2011, with the land area for residence increasing from $31 \mathrm{~km}^{2}$ to $62 \mathrm{~km}^{2}$ during the same period. Based on China's sixth census in 2010, housing area 


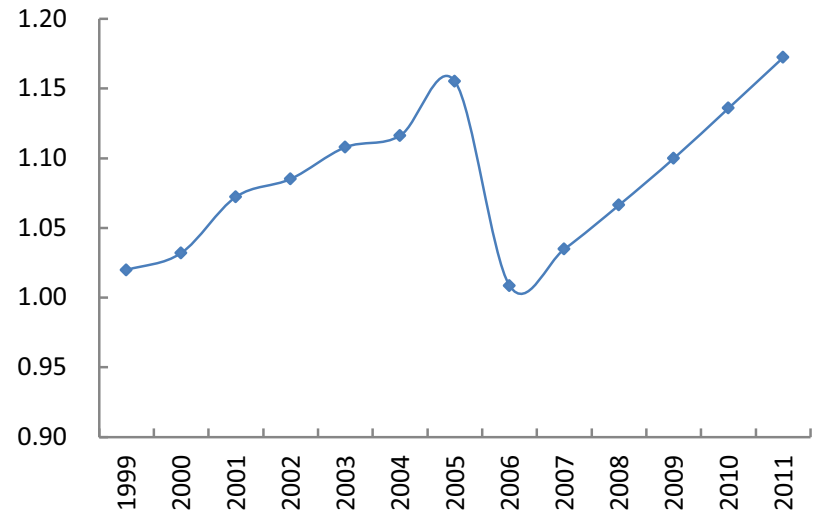

Fig. 7. Urban population density (1999-2011), Baotou city.

per capita is defined as the subsistence type. ${ }^{1}$ Increasing income may thus lead to rigid housing demand, which necessitates the increasing demand of residential land.

From the simulation results, we know that the multiplier effect of urban disposable income per capita on urban expansion is 0.047 , just less than that of LMI. The above analysis thus suggests that the pressure of urban expansion will become more serious as income increases. Hence, we suggest that local government and other departments actively guide the public to develop eco-housing consumption demand to restrain demand for housing construction on urban land.

\subsubsection{Analysis of population density on urban expansion}

Population density is a key metric of urban expansion, and urban sprawl has been defined as the low-density expansion of large urban areas (Inostroza et al., 2013). The simulation results show that the effect of urban population density on urban expansion is a dampening/lagging effect, as current urban population density affects land input in the next year. Its dampening multiplier effect is 0.049. During 1999-2011, the average annual growth rate of urban land was $1.7 \%$, while the average annual growth rate of population density was just $1.3 \%$. Fig. 7 shows that population density was also lower, with the highest population density just $1.17 \times 10^{4}$ people $/ \mathrm{km}^{2}$ in 2011 and the lowest $1.01 \times 10^{4}$ people $/ \mathrm{km}^{2}$. Therefore, it can be inferred that high population density can restrain urban land growth, whereas the effect is not significant for low population density. On the contrary, in some senses, the pattern of urban expansion is urban sprawl.

\subsection{4. $L M I$}

China's LMI is formulated based on its economic and social development, and leads to different land use patterns and changes in different periods (Wang et al., 2012a,b). Land use was planned under China's planned economy before its economic reform and opening up, whereas urban land marketization gradually increased thereafter. Because state land property rights were exercised by local governments as the national trustee, principal-agent risk resulted from the lack of a supervisory mechanism (Zhang, 1996). With the negative consequences of rapid socioeconomic development becoming more serious, China continuously put forward more severe policies and regulations to protect its limited land resources, such as the Basic Farmland Protection Regulation in 1994, the New Land Administration Law in 1998, the Land Use Over-

1 Housing construction area per capita is divided into six types $\left(\mathrm{m}^{2}\right): 8,9-16$, 17-29, 30-49, 50-69, and 70 and over, representing low rent type, economical type, subsistence type, affluent type, comfortable type, and luxurious type, respectively. all Planning in 1999, the Maintain both Economic Development and Land Resources Conservation in 2003.

However, even though China's land strategies and regulations are admirable, they are inefficient in local practice (Bai et al., 2014). Local governments often regard local socioeconomic development, especially GDP growth, as their primary task, downplaying the negative consequences of socioeconomic development. Moreover, financial revenues generated from urban land are distributed to local governments, whose aim, therefore, is not to seek the optimal allocation of land resources for the public. Thus, under this land tax policy, local governments have the preference to increase land requisition and transfer the state land use right in land market. To suppress this preference, the central government in China issued the Notice on Adjusting the Policy of Compensation for the Use of Land for New Construction Land in 2006 and implemented it in 2007 , then the $30 \%$ share of financial revenues from new construction land is distributed to central government. However, the last result was a dramatic growth rate of urban built-up area in 2006, China, and Baotou city. The average growth rate in China and Baotou city reached $3.5 \%$ and $18.75 \%$ respectively.

In this study, the simulation results reveal that LMI plays a crucial role in urban expansion in Baotou city. Its multiplier effect reaches 0.166, suggesting that it is the major driving force among the factors studied. In other words, provided the other factors remain unchanged, a one percentage point increase in the strength of LMI leads to a $0.166 \%$ increase in urban land area. Indeed, its multiplier effect is greater than those of urban disposable income per capita (0.047) and secondary industry $\left(\right.$ Indu $_{2000}=0.012$; Indu $\left._{2011}=0.003\right)$ during the same period. This finding implies that urban expansion is primarily decided by LMI, not by socioeconomic development, suggesting that a certain urban sprawl exists in Baotou city.

\subsection{Scenario analysis of LMI}

The results presented thus far allow us to infer that urban expansion in Baotou city during 1999-2011 was extensive expansion or urban sprawl and that LMI played a critical role in urban land growth. Furthermore, given the urgent need for both economic development and environmental protection in Baotou city, to explain how LMI and the other major factors influence urban expansion in order to optimize LMI arrangements and realize newstyle urbanization, we carry out a scenario analysis as follows:

(1) If $\frac{\Delta L M I_{t}}{L M I_{t}}=0$, when $\frac{\Delta \operatorname{Pop}_{(t-1)}}{\operatorname{Pop}_{(t-1)}}=1.15 \%, \frac{\Delta I n d u 2_{t}}{I n d u 2_{t}}=24.36 \%$, $\frac{\Delta \operatorname{Indu} 3_{t}}{\operatorname{Indu} 3_{t}}=31.02 \%, \frac{\Delta \operatorname{Lnc}(t-1)}{\operatorname{Lnc}(t-1)}=18.99 \%$ at their real average annual grown rate, respectively.

Then, the urban land change rate $\left(\frac{\Delta \text { Land }_{t}}{\text { Land }_{t}}\right)$ equals $\left(0.84 \%-\frac{0.32 \%}{\text { LnTec }_{t}}\right)$ in year $\mathrm{t}$.

$\Rightarrow \frac{\Delta \text { Land }_{t}}{\text { Land }_{t}}=0$, only when Tec $_{t} \leq 1.47$.

Finally, based on technological progress data, we can infer that Land $_{2011}=157.71 \mathrm{~km}^{2}$ in 2011, far less than the real urban land area $\left(185.1 \mathrm{~km}^{2}\right)$. According to these data in Baotou city, urban land retained the same area before $2003\left(\mathrm{Tec}_{2002}=1.185\right.$; $\mathrm{Tec}_{2003}=1.669$ ). The urban land growth rate was $5.1 \%$ from 1999 to 2011.

(2) If $\frac{\Delta L M I_{t}}{L M I_{t}}=1 \%$, when $\frac{\Delta P o p_{(t-1)}}{\operatorname{Pop}_{(t-1)}}=1.15 \%, \frac{\Delta I n d u 2_{t}}{\operatorname{Indu2} t}=24.36 \%$, $\frac{\Delta \operatorname{Indu} 3_{t}}{\operatorname{Indu} 3_{t}}=31.02 \%$,

$\frac{\Delta \operatorname{Lnc}(t-1)}{\operatorname{Lnc}(t-1)}=18.99 \%$ at their real average annual grown rate, respectively.

Then, $\frac{\Delta \text { Land }_{t}}{\text { Land }_{t}}=1.006 \%-\frac{0.32 \%}{\text { LnTect }_{t}}, \Rightarrow \frac{\Delta \text { Land }_{t}}{\text { Land }_{t}}=0$, only when Tec $_{t} \leq$ 1.37 .

Therefore, Land $_{2011}=166.44 \mathrm{~km}^{2}$ in 2011 , less than the real urban land area $\left(185.1 \mathrm{~km}^{2}\right)$. According to technological progress 
in Baotou city, we know that urban land retained the same area before $2003\left(\mathrm{Tec}_{2002}=1.185\right.$; $\left.\mathrm{Tec}_{2003}=1.669\right)$. The growth rate of urban expansion was $11.0 \%$ from 1999 to 2011.

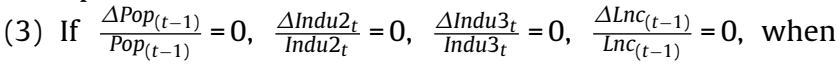
$\frac{\Delta L M I_{2006}}{L M I_{2006}}=171.83 \%$, and $\frac{\Delta L M I_{t}}{L M I_{t}}=0, t \neq 2006$ at the real change situation.

Then, $\frac{\Delta \text { Land }_{2006}}{\text { Land }_{2006}}=28.52 \%$ and $\frac{\Delta \text { Land }_{t}}{\text { Land }_{t}}=0, t \neq 2006$.

Finally, the urban land area in 2011 was $192.8 \mathrm{~km}^{2}$.

Based on above scenario analysis, the following three main results can be inferred:

1. In Inner Mongolia, the profound and unsustainable landscape transformations during the past 50 years have been driven primarily by land use policies (Wu et al., 2015). In this case study, our simulation results identify that LMI played a significant role in urban expansion during the urbanization in Baotou city from 1999 to 2011. If the socioeconomic factors have a zero growth rate and the land government situation changes with reality, urban land would expand by $28.5 \%$ to an area of $192.8 \mathrm{~km}^{2}$.

2. Local socioeconomic development does not result in urban sprawl under the current developing situation. If the strength of LMI did not change and other socioeconomic factors grew in line with their real status, urban land would have expanded by $5.1 \%$ from 1999 to 2011 to an area of $157.7 \mathrm{~km}^{2}$. Nevertheless, if the strength of LMI had intensified by $1 \%$, urban land would have grown by $11.0 \%$ to an area of $166.44 \mathrm{~km}^{2}$ in 2011 .

3. He et al. (2008) pointed out that technological progress can delay the advent of optimal urban expansion. The presented scenario analysis suggests that technological progress has a positive effect on urban expansion. This result fits with reality because Baotou city is a resource-based city focused on heavy/chemical industry. With continuing technological progress, more natural resources carried by land, especially mineral resources, have been exploited, leading more land to be developed as mineral, industrial, and residential land. In some senses, technological progress is extensive since it promotes scale economies compared with industrial transformation and/or the optimization of the industrial structure.

\section{Conclusion and discussion}

This study constructed an endogenous growth model to quantify and investigate the driving forces of urban expansion in Baotou city, China. During 1999-2011, urban land expanded from $150 \mathrm{~km}^{2}$ to $185 \mathrm{~km}^{2}$ at the expense of farmland $\left(40 \mathrm{~km}^{2}\right)$ and grassland $\left(145 \mathrm{~km}^{2}\right)$. The major endogenous factors affecting urban expansion are LMI, urban disposable income per capita, the secondary and tertiary industry, technological progress, and population density. However, LMI plays the most important role during urban expansion. As a result, urban land supply exceeds demand for socioeconomic development, which leads urban sprawl.

China's urban expansion has different paths nationwide (Chen et al., 2013; Quan et al.,2015). Huang et al., (2015) indicated that population density has a positive relationship with urban expansion in China. By contrast, it has a dampening and lagging effect on urban expansion in Baotou. This finding fits well with the reality in western China, where population density is far lower than that in eastern China or in other developed regions in the country. Based on the dampening/lagging effects of population density on urban expansion, we suggest that the government should guide population density and urban land planning to accommodate urban development while minimizing the conversion of rural land into urban land.
In this model, technological progress, as a major driving force of urban expansion, has an active effect on optimizing industry-level scale economies, without a significant effect on industrial transformation. Technological progress has a positive effect on urban expansion since it promotes scale economies in the secondary industry. Hence, economic development in Baotou city largely depends on its secondary industry (i.e., heavy/chemical industry). Over the same period, the dampening effect on urban expansion from the tertiary industry reveals such land is too excessive or that other resources are insufficient. Further, the efficiency of resource allocation is inefficient in the tertiary industry. According to this degree of industrial development, we suggest that technological progress should be guided to promote industry transformation and optimize the industry structure.

Overall, the presented simulation results and analysis provide strong support for our theoretical hypothesis. Our results indicate that LMI has a critical influence on urban expansion. Local governments, as the national trustee, hold the property rights of state land, which easily leads to principal-agent risk, resulting in urban sprawl. Based on this, we suggest that the central government should intensify supervising forces to regulate the behavior of local governments.

Finally, to understand the topic more in depth and promote sustainable urbanization, future studies should aim to investigate urban expansion at wider spatial scales, with a particular focus on the Shanxi-Gansu-Ningxia-Inner Mongolia zone along the Yellow River, and try to uncover the LMI choices that cause the rate of urban land growth of the residual to vary across regions with the same economic development and natural endowments since spatial dependence may influence the role of LMI and socioeconomic development during urban expansion.

This model is efficient and practical. It can be easily used in other NW regions of China to optimize LMI arrangements. However, the eco-environment and natural endowments are not considered in this model.

\section{Funding}

We would like to acknowledge the funding of the National Natural Science Foundation of China (Suocheng Dong, 41271556), the "Belt and Road" key deployment project of Chinese Academy of Sciences, China (ZDRW-ZS-2016-6-5) and the Key Research Institute of Philosophies and Social Sciences in Guangxi Universities, China (15YB001).

\section{Acknowledgments}

This research was supported by the National Natural Science Foundation of China (No. 41271556), "Belt and Road" key deployment project of Chinese Academy of Sciences, China (ZDRWZS-2016-6-5) and the Key Research Institute of Philosophies and Social Sciences in Guangxi Universities, China (15YB001).

\section{Appendix A. Supplementary data}

Supplementary data associated with this article can be found, in the online version, at http://dx.doi.org/10.1016/j.landusepol.2016. 04.021 .

\section{References}

Angel, S., Parent, J., Civco, D.L., Blei, A., Potere, D., 2011. The dimensions of global urban expansion: estimates and projections for all countries, 2000-2050. Prog. Plan. 75 (2), 53-107.

Bai, X., Shi, P., Liu, Y., 2014. Society realizing China's urban dream. Nature 509, $158-160$. 
Chen, M., Liu, W., Tao, X., 2013. Evolution and assessment on China's urbanization 1960-2010: Under-urbanization or over-urbanization? Habitat Int. 38, 25-33.

China Financial 40 People Forum Project Group, 2013. Land institution reform and new-type urbanization. Finan. Res. 5, 114-125 (in Chinese).

Christensen, F.K., 2014. Understanding value changes in the urban development process and the impact of municipal planning. Land Use Pol. 36, 113-121.

Ding, C., 2003. Land policy reform in China Assessment and prospects. Land Use Pol. 20, 109-120.

Dong, S.C., Li, X., et al., 2010. Study on the strategy of eco-economic zone in the Hanxi-Gansu-Ningxia-Inner Mongolia region along the Yellow River. Geogr. Res. 29 (2), 204-213 (in Chinese)

Dorning, M.A., Koch, J., Shoemaker, D.A., Meentemeyer, R.K., 2015. Simulating urbanization scenarios reveals tradeoffs between conservation planning strategies. Land Urban Plan 136, 28-39.

Gao, J.L., Chen, J.L., Su, X., 2013. Urban expansion and its driving mechanism in China: from three main schools' perspectives. Prog. Geogr. 5 (32), 743-754 (in Chinese).

Han, F., 2012. The effect of technology improvement on the intensity of urban land use in Hunan Province. China Land Sci. 26 (5), 9-15 (in Chinese).

He, H., Zhou, J., Wu, Y., Zhang, W., Xie, X., 2008. Modeling the response of surface water quality to the urbanization in Xi'an, China. J. Environ. Manage. 86 (4), 731-749.

Huang, Z., Wei, Y.D., He, C., Li, H., 2015. Urban land expansion under economic transition in China: a multilevel modeling analysis. Habitat Int. 47, 69-82.

Huynh, D., 2015. The misuse of urban planning in Ho Chi Minh city. Habitat Int. 48 $11-19$.

Inostroza, L., Baur, R., Csaplovics, E., 2013. Urban sprawl and fragmentation in Latin America: a dynamic quantification and characterization of spatial patterns. J. Environ. Manage. 115, 87-97.

Jiang, L., Deng, X., Seto, K.C., 2013. The impact of urban expansion on agricultural land use intensity in China. Land Use Pol. 35, 33-39.

Jiang, B., Wang, Y., Wei, C., Gai, X., Qiao, L., 2014. Research on city land use expansion driving factors and spatial expansion mode. J. Arid. Land Res. Environ. 28 (7), 1-6 (in Chinese).

Kuang, W.H., Liu, J.Y., Shao, Q.Q., Sun, C.Y., 2009. Spatio-temporal patterns and driving forces of urban expansion in Beijing central city since 1932. J. Geogr. Inf. Sci. 4, 428-435 (in Chinese).

Kumar, A., Pandey, A.C., Hoda, N., Jeyaseelan, A.T., 2011. Evaluating the long-term urban expansion of Ranchi urban agglomeration, India using geospatial technology. J. Indian Soc. Remote Sens. 39 (2), 213-224.

Leung, C.K.Y., 2001. Relating international trade to the housing market. Rev. Dev. Econ. 5 (2), 328-335.

Li, Z.N., Ye, A.Z., 2000. Advanced Econometrics. Tsinghua University Press, pp. 33-34 (in Chinese).

Li, Z., Lei, J., Li, X.M., Chao, G., Zeng, W.Y., 2011. The features and driving forces of urban expansion in China during 1997-2007. Progr. Geogr. 30 (5), 607-614 (in Chinese).

Liu, H.P., Zhang, A.L., 2008. Review of progress of control on urban land expansion in foreign countries. China Land Sci. 5, 72-76 (in Chinese).
Mondal, B., Das, D.N., Dolui, G., 2015. Modeling spatial variation of explanatory factors of urban expansion of Kolkata: a geographically weighted regression approach. Model Earth Syst. Environ. 1 (4), 1-13.

Quan, B., Bai, Y., Römkens, M.J.M., Chang, K.T., Song, H., Guo, T., Lei, S., 2015. Urban land expansion in quanzhou city. China 1995-2010. Habitat Int. 48, 131-139.

Romer, Paul M., 1994. The origins of endogenous growth. J. Econ. Perspect. 8 (1), $3-22$.

Sachs, J.D., Larrain, F.B., 2003. Macroeconomics in the Global Economy. Shanghai Renmin Press, Shanghai (In Chinese).

Seto, K.C., Fragkias, M., Güneralp, B., Reilly, M.K., 2011. A meta-analysis of global urban land expansion. PLoS One 6 (8), e23777.

Taylor, N., 1998. Urban Planning Theory Since 1945. SAGE Publications, London.

United Nations, 2014. World Urbanization Prospects, the 2014 Revision (Available at: http://esa.un.org/unpd/wup/Highlights/WUP2014-Highlights.pdf).

Upton, V., O’Donoghue, C., Ryan, M., 2014. The physical, economic and policy drivers of land conversion to forestry in Ireland. J. Environ. Manage. 132, 79-86.

Verburg, P.H., Veldkamp, A., Fresco, L.O., 1999. Simulation of changes in the spatial pattern of land use in China. Appl. Geogr. 19 (3), 211-233.

Wang, C.P., Wang, H.W., Li, C.M., Dong, R.C., 2012a. Analysis of the spatial expansion characteristics of major urban agglomerations in China using DMSP/OLS images. Acta Ecol. Sin. 3 (23), 942-953 (in Chinese).

Wang, J., Chen, Y., Shao, X., Zhang, Y., Cao, Y., 2012b. Land-use changes and policy dimension driving forces in China Present, trend and future. Land Use Pol. 29, 737-749.

Wei, Y.D., Ye, X., 2014. Urbanization: urban land expansion and environmental change in China. Stoch. Environ. Res. Risk Assess. 28, 757-765.

Wu, Y.J., Dong, S.C., 2010. Dynamic change patterns of farmland in China from the perspective of resource economics China population. Res. Environ. 5 (20), 5-8 (in Chinese).

Wu, D.Q., Liu, J., Wang, S.J., Wang, R.Q., 2010. Simulating urban expansion by coupling a stochastic cellular automata model and socioeconomic indicators. Stoch. Environ. Res. Risk Assess. 24, 235-245.

Wu, J., Zhang, Q., Li, A., Liang, C., 2015. Historical landscape dynamics of Inner Mongolia: patterns, drivers, and impacts. Landscape Ecol., http://dx.doi.org/10. 1007/s10980-015-0209-1.

Xiao, J., Shen, Y., Ge, J., Tateishi, R., Tang, C., Liang, Y., Huang, Z., 2006. Evaluating urban expansion and land use change in Shijiazhuang China, by using GIS and remote sensing. Landscape Urban Plan 75, 69-80.

Zeng, C., Zhang, M.D., Cui, J.X., He, S.W., 2015. Monitoring and modeling urban expansion: a spatially explicit and multi-scale perspective. Cities 43, 92-103.

Zhang, W.Y., 1996. Game Theory and Information Economics. Shanghai Renmin Press, Shanghai.

Zhao, K., Zhang, X., Zhang, B.X., 2014. An empirical analysis on relationship between urbanization and urban construction land: based on time series data from 1982 to 2011 in Mainland China. J. Huazhong Agric. Univ. 2, 107-113 (in Chinese).

Zhao, S., Decheng, Z., Chao, Z., Wenyuan, Q., Jiajia, Z., Yan, S., Dian, H., Wenjia, W., Shuguang, L., 2015. Rates and patterns of urban expansion in China's 32 major cities over the past three decades. Landsc. Ecol. 30, 1541-1559. 